\title{
Polycyclic aromatic hydrocarbon (PAHs) and hopanes in stranded tar-balls on the coasts of Peninsular Malaysia: applications of biomarkers for identifying sources of oil pollution
}

\begin{abstract}
Malaysian coasts are subjected to various threats of petroleum pollution including routine and accidental oil spill from tankers, spillage of crude oils from inland and offshore oil fields, and run-off from land-based human activities. Due to its strategic location, the Straits of Malacca serves as a major shipping lane. This paper expands the utility of biomarker compounds, hopanes, in identifying the source of tar-balls stranded on Malaysian coasts. 20 tar-ball samples collected from the east and west coast were analyzed for hopanes and polycyclic aromatic hydrocarbons (PAHs). Four of the 13 tar-ball samples collected from the west coast of Peninsular Malaysia were identified as the Middle East crude oil (MECO) based on their biomarker signatures, suggesting tanker-derived sources significantly contributing the petroleum pollution in the Straits of Malacca. The tar-balls found on the east coast seem to originate from the offshore oil platforms in the South China Sea. The presence of South East Asian crude oil (SEACO) tar-balls on the west coast carry several plausible explanations. Some of the tar-balls could have been transported via sea currents from the east coast. The tankers carrying SEACO to other countries could have accidentally spilt the oil as well. Furthermore, discharge of tank washings and ballast water from the tankers were suggested based on the abundance in higher molecular weight n-alkanes and the absence of unresolved complex mixture (UCM) in the tar-ball samples. The other possibilities are that the tar-balls may have been originated from the Sumatran oil fields and spillage of domestic oil from oil refineries in Port Dickson and Malacca. The results of PAHs analysis suggest that all the tarball samples have undergone various extent of weathering through evaporation, dissolution and photo-oxidation.
\end{abstract}

Keyword: Straits of Malacca; Tar-balls; Hopanes; PAHs; Biomarkers; Weathering; Oil pollution sources 